\section{Pferdeenzephalitis-Viren, venezolanische} (VEEV)

\section{W. Stöcker}

Euroimmun Medizinische Labordiagnostika AG, Lübeck, Deutschland

Englischer Begriff Venezuelan equine encephalitis virus

Beschreibung des Erregers Familie: Togaviridae; Gattung: Alphavirus; Art: Venezuelan equine encephalitis virus. Plusstrang-RNA-Genom.

Erkrankungen Vorkommen: Nördliches Südamerika, Zentralamerika.

Vektoren: Stechmücken (Culex ssp., Aedes ssp., Haemagogus ssp.).

Wirte: Unterschiedliche Warmblüter dienen als Virusreservoir (Nagetiere: enzootischer Infektionszyklus; Pferde: epizootischer Infektionszyklus). Von Bedeutung sind Epidemien bei Pferden, die Ursprung von Epidemien in menschlichen Populationen sein können.

Klinik: Infektionen verlaufen in den meisten Fällen ohne Symptome oder mild mit leichten Kopfschmerzen; in etwa 1:100 Fällen treten schwere Verläufe mit hohem Fieber, Meningitis und Enzephalitis auf; bei diesen Patienten liegt die Letalitätsrate bei $10 \%$; neurologische Folgeschäden bei Überlebenden sind möglich.

Analytik Direktnachweis: Nachweis viraler RNA durch RT-PCR (Polymerase-Kettenreaktion), Virusanzucht.
Serologie: Nachweis spezifischer Antikörper (IgM, IgG) in Serum oder Liquor durch u. a. > Enzyme-linked Immunosorbentassay, Radioimmunoassay oder $>$ Neutralisationstest.

Probenmaterial Direktnachweis: Blut und Blutbestandteile, Gewebe oder Liquor. Das Material sollte bis zur Weiterverarbeitung bei +4 bis $+8{ }^{\circ} \mathrm{C}$ aufbewahrt werden.

Serologie: Serum oder Plasma für den Nachweis der Antikörper sind bei $+4{ }^{\circ} \mathrm{C}$ bis zu 2 Wochen lang beständig, bei $-20{ }^{\circ} \mathrm{C}$ über Monate und Jahre hinweg. Zur Tiefkühlkonservierung des IgM kann man den Proben 80 \% gepuffertes Glyzerin beifügen.

Diagnostische Wertigkeit In erster Linie sind die Anamnese und der Nachweis spezifischer Antikörper (IgG, IgM) von entscheidender Bedeutung für die Diagnose. Für die serologische Untersuchung sind Speziallaboratorien empfehlenswert.

Differenzialdiagnose: Infektionen mit Herpes-Viren, Coxsackie-Viren, Dengue-Viren oder weiteren Arboviren, die das ZNS befallen.

\section{Literatur}

Center for Food Security and Public Health. Iowa State University (2015) Animal disease information. Equine encephalitides. Latest update Jan 2015. Technical factsheet: eastern, western and venezuelan equine encephalomyelitis. http://www.cfsph.iastate.edu/Factsheets/ pdfs/easter_wester_venezuelan_equine_encephalomyelitis.pdf. Zugegriffen am 11.04 .2017

Robert-Koch-Institut, Berlin (2011) Steckbriefe seltener und importierter Infektionskrankheiten. Robert-Koch-Institut, Berlin 